( 2018 , The Authors. Published by FASS Inc. and Elsevier Inc. on behalf of the American Dairy Science Association ${ }^{\circledR}$.

This is an open access article under the CC BY-NC-ND license (http://creativecommons.org/licenses/by-nc-nd/4.0/).

\title{
Genome-wide association study of milk fatty acid composition in Italian Simmental and Italian Holstein cows using single nucleotide polymorphism arrays
}

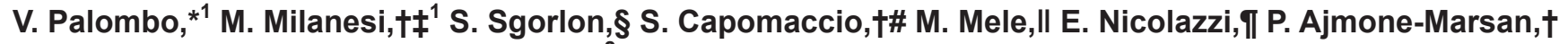 \\ F. Pilla, ${ }^{*}$ B. Stefanon, $\S$ and M. D'Andrea*2 \\ *Dipartimento Agricoltura, Ambiente e Alimenti, Università degli Studi del Molise, via De Sanctis snc, 86100 Campobasso, Italy \\ †Istituto di Zootecnica, Università Cattolica del Sacro Cuore, via Emilia Parmense, 84, 29122 Piacenza, Italy \\ ‡Department of Support, Production and Animal Health, School of Veterinary Medicine, São Paulo State University, Araçatuba, \\ Rua Clóvis Pestana, 793-Dona Amelia, Araçatuba-SP, 16050-680 São Paulo, Brazil \\ §Dipartimento di Scienze Agroambientali, Alimentari e Animali, Università di Udine, via delle Scienze, 208, 33100 Udine, Italy \\ \#Dipartimento di Medicina Veterinaria, Università di Perugia, Via San Costanzo 4, 06126 Perugia, Italy \\ IIDipartimento di Scienze Agrarie, Alimentari e Agro-ambientali, Università di Pisa, Via del Borghetto, 80, 56124 Pisa, Italy \\ IPTP Science Park, Via Einstein-Loc. Cascina Codazza, 26900 Lodi, Italy
}

\begin{abstract}
Bovine milk is important for human nutrition, but its fat content is often criticized as a risk factor in cardiovascular disease. Selective breeding programs could be used to alter the fatty acid (FA) composition of bovine milk to improve the healthiness of dairy products for human consumption. Here, we performed a genome-wide association study (GWAS) on bovine milk to identify genomic regions or specific genes associated with FA profile and to investigate genetic differences between the Italian Simmental (IS) and Italian Holstein (IH) breeds. To achieve this, we first characterized milk samples from 416 IS cows and 436 IH cows for their fat profile by gas chromatography. Subjects were genotyped with single nucleotide polymorphism array and a single-marker regression model for GWAS was performed. Our findings confirm previously reported quantitative trait loci strongly associated with bovine milk fat composition. More specifically, our GWAS results revealed significant signals on chromosomes Bos taurus autosome 19 and 26 for milk FA. Further analysis using a gene-centric approach and pathway meta-analysis identified not only some well-known genes underlying quantitative trait loci for milk FA components, such as FASN, SCD, and DGAT1, but also other significant candidate genes, including some with functional roles in pathways related to "Lipid metabolism." Highlighted genes related to FA profile include ECI2, PCYT2, DCXR, G6PC3, PYCR1, and ALG12 in IS, and CYP17A1, ACO2, PI4K2A, GOT1,
\end{abstract}

Received January 8, 2018.

Accepted August 3, 2018.

${ }^{1}$ These authors contributed equally to this paper.

${ }^{2}$ Corresponding author: dandrea@unimol.it
GPT, NT5C2, PDE6G, POLR3H, and COX15 in IH. Overall, the breed-specific association outcomes reflect differences in the genetic backgrounds of the IS and IH breeds and their selective breeding histories.

Key words: milk lipid content, genome-wide association study, cow

\section{INTRODUCTION}

Bovine milk is important for human nutrition. Among its components, fat is the main source of energy and it influences the taste of milk and dairy products (Fenelon and Guinee, 1999; Esposito et al., 2014; Martini et al., 2016). Nevertheless, milk fat is often criticized due to its high content of SFA, which are claimed to be associated with elevated blood cholesterol, heart disease, weight gain, and obesity (Shingfield et al., 2013; Tullo et al., 2014; Pulina et al., 2017). Conversely, MUFA are considered to have a favorable effect on human health because of their cholesterol-lowering properties (Schwingshackl and Hoffmann, 2012). Similarly, PUFA, especially the n-6 and n-3 series, are considered to be beneficial because they influence the levels of plasma lipids involved in cardiac and endothelial functions toward preserving coronary health (FAO, 2010; Li et al., 2014; Zhang et al., 2016). Furthermore, special attention is paid to CLA (long-chain fatty acids) due to their supposed role in the modulation of plasma lipid concentrations; CLA also have anticarcinogenic and anti-inflammatory effects, as shown in vitro and in animal model studies (Parodi, 1999; Haug et al., 2007).

In dairy cows, typical milk fat content is about $70 \%$ SFA, 25\% MUFA, and 5\% PUFA, which departs considerably from the ideal fatty acid profile for human health (8\% SFA, $82 \%$ MUFA, and 10\% PUFA; Bilal et al., 2014). To improve the healthiness of human diets 
and to satisfy consumer demand, it is expected that a premium price for milk quality would include changes to the composition of the lipid and protein fractions of marketed milk (Tullo et al., 2014).

It is important to highlight that short- and mediumchain ( $\mathrm{C} 4$ to $\mathrm{C} 16)$ saturated and monounsaturated milk fatty acids (FA) are largely synthesized de novo in the mammary gland and show moderate to high heritability. In contrast, long-chain FA (C18 or more carbon atoms) are derived from circulating plasma lipids, which originate from the diet and from body fat metabolism and show low to moderate heritability (Schennink et al., 2009b; Stoop et al., 2009; Buitenhuis et al., 2014). In fact, these differences in heritability between longchain FA metabolism versus short/medium-chain FA metabolism create the opportunity to modify milk FA composition by selective animal breeding. If realized, such improved breeds would represent a more permanent and reliable solution than changes in livestock production systems, offering at the same time more product choices to consumers (Mele et al., 2007; Schennink et al., 2009b; Bilal et al., 2014).

Several genes are known to be involved in FA synthesis (e.g., DGAT1, FASN, and $S C D$ ) and numerous studies have found genetic variants associated with altered FA profiles (Grisart et al., 2002; Moioli et al., 2007; Schennink et al., 2007, 2008). However, due to the complexity of the biological pathways involved in FA synthesis, these major genes cannot explain all the fat-composition variability in milk. Genome-wide association study (GWAS) is a promising tool to investigate the genetic contribution to variability in milk fat composition. Genomic regions or genes identified as being associated with FA could be used to modify the FA composition of milk through marker-assisted selection.

The classical GWAS approach aims to identify genomic regions associated with the investigated trait (QTL), but it is limited by the nature of the SNP information considered [i.e., known investigated variants (tag-SNP) are associated with unknown causative SNP, but the link with possible functional units (genes) is lost (Capomaccio et al., 2015a)]. To improve the usability of the results and enhance low-signal catching, various strategies can be applied. For example, haplotypes could be used instead of single markers to better pinpoint the associated genomic regions (Utsunomiya et al., 2017). Another approach, implemented postGWAS, involves fine dissection of the associated signals in silico (Capomaccio et al., 2015b; Pegolo et al., 2018). At the same time, the investigation of genetic differences in phenotypically diverse breeds is a recognized strategy to reveal genes and related pathways that underlie complex traits of interest (D'Andrea et al., 2011), including milk FA profiles (Buitenhuis et al., 2014). In this regard, Italian Simmental (IS) and Italian Holstein (IH) represent 2 breeds with different productive characteristics and divergent selective breeding histories, as well as distinct genetic backgrounds (Bomba et al., 2015; Marras et al., 2015). Italian Simmental is a dualpurpose cattle type, well adaptable to extensive systems in mountainous areas (www.anapri.it). Italian Holstein is a dairy cow intensively selected for high milk yield in intensive production systems (www.anafi.it). Limited comparative data are available in the literature for these 2 breeds in terms of milk FA composition. However, significant differences in milk FA content between the Polish Simmental and Polish Holstein Friesian were previously reported (Adamska et al., 2016).

The identification of common genes involved in the control of a trait of interest between 2 breeds is challenging due to breed-specific selection targets that can result in significant differences at the genomic level (Bomba et al., 2015; Marras et al., 2015). Moreover, alleles segregating in one breed may be fixed in the other; or even when the same alleles are segregating in both breeds, the genetic background may change their phenotypic effects (Capomaccio et al., 2015a). Multibreed GWAS helps in QTL detection only when the same QTL are shared across breeds (van den Berg et al., 2016). For example, Raven and colleagues found a reduction in power when Holstein and Jersey data were combined, compared with within-breed GWAS results (Raven et al., 2014). To overcome this problem, in addition to using a classical GWAS approach, we applied post-GWAS analyses to increase the discovery power in both breeds. These methods included an initial genebased approach, multi-species gene-based association suite (MUGBAS; Capomaccio et al., 2015b), followed by pathways interaction analysis [PIA; V. Palombo, M. Milanesi, G. Sferra (Dipartimento di Bioscienze e Territorio, Università degli Studi del Molise, Pesche, Italy), S. Capomaccio, S. Sgorlon, M. D'Andrea, unpublished data]. The former used the single-SNP GWAS results to calculate a gene-wise $P$-value. Briefly, the gene-wise test statistic condenses $P$-values of a SNP subset (within gene boundaries) by weighting local linkage disequilibrium (LD; Capomaccio et al., 2015a,b). As reported by Capomaccio et al. (2015a,b), the gene-centric approach improves the power of the analyses by rescuing signals falling below the genomewide threshold in single-SNP GWAS. The latter uses the list of significant genes obtained with MUGBAS and investigates their relationships, taking into account upstream and downstream pathways connected to the trait(s) of interest (here, "Lipid metabolism" pathway). That is, the gene is evaluated for its functionality in the pathways involved in the trait(s). 
Here, we applied this pipeline on IS and IH lactating cows to find new QTL and genes affecting breed-specific FA composition and to further elucidate genetic differences and similarities between the 2 breeds.

\section{MATERIALS AND METHODS}

\section{Experimental Population}

In total, 416 IS and 436 IH cows from 10 commercial dairy farms located in the northeast part of the Po Valley (Italy) were enrolled in the study. The farms used homogeneous management practices and ration compositions, as determined in consultation with the local Farm and Breeder Association (Associazione Allevatori del Friuli Venezia Giulia, Codroipo, Italy; www.aafvg .it), which also provided information on individual milk records, reproductive parameters and management aspects. The herd sizes ranged from 157 to 654 cows. The inclusion criteria for enrolment were clinically healthy cow and preferentially in mid-lactation. The average DIM were $153( \pm 70)$ for IS and $167( \pm 63)$ for IH. All lactating cows were housed in free stalls with cubicles, and the milking parlors were similar among farms. Cows had free access to water, and ad libitum TMR, based on corn silage and formulated to meet nutrient requirements, was offered twice a day, after the morning and afternoon milkings.

On the day of official milk recording by the Breeder Association, a $100-\mathrm{mL}$ sample of milk was collected from each cow at the morning milking. A 50-mL aliquot was transferred into a tube containing preservative and used for analysis of protein, fat, and lactose and for SCC determination. The other 50-mL aliquot of milk was transferred to a tube without preservative, frozen within $2 \mathrm{~h}$, and stored at $-20^{\circ} \mathrm{C}$ for FA analysis. Peripheral blood samples were collected and stored at $-20^{\circ} \mathrm{C}$ before DNA isolation. Animals were also classified for parity, DIM, milk yield, fat, and protein percentage content (Supplemental Table S1; https://doi.org/10 $.3168 /$ jds.2018-14413); for both breeds, data were provided by the national breeder associations (ANAPRI for IS and ANAFI for IH).

\section{Fatty Acid Analysis}

Milk fat was extracted according to Buccioni et al. (2010) and FAME were prepared with a base-catalyzed transesterification reaction according to Christie (1982). The FAME were separated and identified by GC according to Buccioni et al. (2015).

The desaturation index (DI) was calculated according to the following formulas:

$$
\begin{aligned}
& \mathrm{DI}=(\text { cis-9 10:1)/(10:0 + cis-9 10:1) } \\
& \mathrm{DI}=(\text { cis-9 14:1)/(14:0 + cis-9 14:1) } \\
& \mathrm{DI}=(\text { cis-9 16:1)/(16:0 + cis-9 16:1) } \\
& \mathrm{DI}=(\text { cis-9 18:1)/(18:0 + cis-9 18:1) } \\
& \mathrm{DI}=(\text { cis-9,trans-11 18:2)/ } \\
& \text { (trans-11 18:1 + cis-9,trans-11 18:2). }
\end{aligned}
$$

All results were expressed in grams per $100 \mathrm{~g}$ of FA (Supplemental Table S1; https://doi.org/10.3168/jds .2018-14413).

\section{Statistical Analysis of Phenotypes}

Fatty acid traits were compared between the breeds with the Welch 2-sample $t$-test $\mathrm{R}$ function to estimate significant differences ( $\mathrm{R}$ Development Core Team, 2006). Variance components were calculated within the breeds separately by adopting a linear mixed model performed with the MIXED procedure in SPSS software (version 22.0, IBM SPSS Statistics for Windows, Armonk, NY) using the following model:

$$
\begin{aligned}
Y_{i j k}= & \mu+\text { yield }_{i}+F K g_{i}+P K g_{i}+\log \left(S C C_{i}\right) \\
& + \text { DIM }_{i}+\text { parity }_{j}+\text { farm }_{k}+e_{i j k},
\end{aligned}
$$

where $Y_{i j k}$ is the phenotype of cow $i$ in farm $k$ and class of calving $j ; \mu$ is the overall mean; yield is the covariate effect of milk yield; $F K g$ and $P K g$ are the covariate effect of fat and protein content, respectively; $S C C$ is the covariate effect of SCC; DIM is the covariate describing the effect of DIM; parity is the fixed effect of calving, in which before statistical analysis the animals were classified for parity with the ordinal values of 1 for first calving, 2 for second calving, and 3 for third or greater calving; farm is the random effect of farm distributed as $N\left(\mathbf{0}, \mathbf{I} \sigma^{2}\right.$ farm $)$, with identity matrix $\mathbf{I}$ and farm variance $\sigma_{\text {farm }}^{2}$; and $\varepsilon$ is the random residual distributed as $N(\mathbf{0}$, $\mathbf{I} \sigma_{\varepsilon}^{2}$ ), with identity matrix $\mathbf{I}$ and farm variance $\sigma_{\varepsilon}^{2}$.

For each trait, the heritability was calculated by ASreml software (Gilmour et al., 2009), using the same data (Supplemental Table S1) and the model described above. All phenotypic distributions were tested for normality using a Shapiro-Wilk test and nonnormal phenotypes were adjusted by truncation of outliers $( \pm 3$ times SD, and when necessary, the first 5 values that fall below first quartile, Q1, and above the third quartile, Q3) or by log-transformation. 


\section{Genotyping and Quality Control}

Genomic DNA was isolated from whole blood using a GenElute Mammalian Genomic DNA Miniprep Kit (Sigma-Aldrich, St. Louis, MO). After extraction, the quality and quantity of nucleic acid were assessed by electrophoresis and spectrophotometry. The DNA was stored at $-20^{\circ} \mathrm{C}$. Fifty nanograms of genomic DNA was sent to the genotyping facility (GeneSeek, Lincoln, NE) for marker analysis. In total, 152 IS cows were genotyped with the BovineHD Genotyping BeadChip (BovineHD, 777,000 SNP) (Illumina, San Diego, CA); the rest of the IS cows were genotyped with the GeneSeek GGP Bovine 150K array from Neogene (Bovine150K, 150,000 SNP). All IH subjects were genotyped with the GeneSeek GGP Bovine 150K array from Neogene (Bovine150K). Before the imputation phase, genotypes were subjected to quality control by excluding markers with more than $10 \%$ missing data, minor allele frequency less than $1 \%$, and duplicate physical positions. Subjects with more than $10 \%$ missing data were also removed. The IS cows genotyped with the BovineHD chip were de-imputed to the lower density by using BEAGLE software v4.0 (Browning and Browning, 2007, 2016) to generate uniform SNPchip densities between the breeds. Briefly, the common markers between the Bovine150K chip and the BovineHD chip were first extracted, and then the noncommon ones were imputed. For IH, only missing genotype imputation and phasing were performed. Allelic correlation $\left(\mathbf{r}^{2}\right)$ estimated by BEAGLE was used to evaluate the imputation accuracy. Markers with $\mathrm{r}^{2}$ lower than 0.75 were excluded. After imputation, the genotypes were quality checked. The SNP with minor allele frequency lower than $5 \%$ or with a Hardy-Weinberg equilibrium $P$-value lower than $10^{-6}$ were excluded. Subjects with lower or higher observed heterozygosity (ObsHet; average \pm 4SD; 0.3352 $\geq$ ObsHet $\geq 0.4494$ ) or not pure [i.e., more than $20 \%$ of the other breed's genetic component evaluated, using K2 from Admixture software v1.3 (Alexander et al., 2009)] were excluded.

The final data sets consisted of 118,135 SNP in 416 IS animals and 121,165 SNP in $436 \mathrm{IH}$ animals.

\section{Genome-Wide Association Analysis}

Genome-wide association analysis was carried out based on regression of phenotypes on the genotypes of animals for one SNP at a time. For this purpose, a genome-wide rapid analysis using mixed model and score (GRAMMAS) test was carried out (Aulchenko et al., 2007a) in the R package GenABEL (Aulchenko et al., 2007b) as described by the following general formula:

$$
\mathbf{Y}=\mu+\mathbf{X b}+\mathbf{S a}+\mathbf{Z u}+\varepsilon,
$$

where $\mathbf{Y}$ is the vector of trait values (milk fatty acids - FA); $\mu$ is the overall mean; $\mathbf{b}$ is the vector of fixed effects [milk yield, fat and protein content, $\log (\mathrm{SCC})$, parity, DIM, and farm effect]; $\mathbf{a}$ is the fixed effect of the SNP genotype; $\mathbf{u}$ and $\varepsilon$ are vectors of random additive polygenic effects and random residuals, respectively, $u$ $\sim N\left(\mathbf{0}, \mathbf{A} \sigma^{2}{ }_{\mathrm{a}}\right)$ and $\varepsilon \sim N\left(\mathbf{0}, \mathbf{I} \sigma_{\varepsilon}^{2}\right)$, where $\mathbf{A}$ is the additive genetic relationship matrix estimated from SNP data using the ibs function in GenABEL (Aulchenko et al., 2007b), $\mathbf{I}$ is an identity matrix, and $\sigma^{2}{ }_{a}$ and $\sigma^{2}{ }_{8}$ are the additive genetic and residual error variances, respectively. $\mathbf{X}, \mathbf{S}$, and $\mathbf{Z}$ are the related incidence matrices. The associations were deemed to be significant for Bonferroni-corrected genome-wide significant thresholds at 0.05 (equivalent to $4.23245 \times 10^{-7}$ in the IS population and $4.12660 \times 10^{-7}$ in the IH population). Furthermore, a GWAS analysis was performed for the trait milk fat percentage content (FP) using the same model, but considering only parity, DIM, and farm as fixed effects.

\section{Gene-Based Association Analysis}

A limitation of GWAS is the stringent significance threshold often applied to correct for multiple testing. As a result, a large proportion of genes with small effects are disregarded, with consequent overestimation of the effects of major genes (Capomaccio et al., 2015a). To overcome this limitation, the post-GWAS MUGBAS procedure was used to pinpoint candidate genes starting from single-SNP GWAS results (Capomaccio et al., 2015b). Briefly, MUGBAS takes into account both the SNP significance results and specific gene annotation information (Bos taurus reference genome assembly UMDv3.1; https://www.ensembl.org/Bos_taurus/Info/ Annotation), and once gene boundaries are defined, MUGBAS condenses the $P$-values of a SNP subset by weighting local $\mathrm{LD}$ and then estimates a gene-based association $P$-value. In our analysis, the gene boundaries were artificially increased on both sides (100 kbp) to capture regulatory motifs as well. For each gene, a gene-wise $P$-value and false discovery rate $\mathrm{q}$-value were calculated. Associations with false discovery rate q-values less than or equal to 0.05 were considered as significant.

\section{Pathways Interaction Analysis}

To infer the most probable candidate among the significant gene list uncovered with MUGBAS, a PIA 
was performed [V. Palombo, M. Milanesi, G. Sferra (Dipartimento di Bioscienze e Territorio, Università degli Studi del Molise, Pesche, Italy), S. Capomaccio, S. Sgorlon, and M. D'Andrea, unpublished data]. Briefly, PIA is an in-house R-package based on gene relationship investigations, taking into account upstream and downstream pathway interactions. For this purpose, the significant gene list is ordered into respective Kyoto Encyclopedia of Genes and Genomes (KEGG) metabolic pathways (Kanehisa and Goto, 2000). Once pathways strongly related to the trait of interest are chosen (first degree interaction), a dependent interaction network is automatically created by selecting the relative up/ downstream pathways [from 2 (second degree interaction) to $n$ degrees of interactions] based on information available in the KEGG databases (Kanehisa and Goto, 2000). Ultimately, genes falling inside the interaction pathways are considered good candidates for the trait of interest, having both positional and functional evidence in their support. In the present study, after selecting KEGG "Lipid metabolism" pathway as the first degree interaction, a PIA was undertaken based on 3 degrees of interactions considering the complexity of gene networks driving bovine milk fat synthesis (Bionaz and Loor, 2008).

\section{RESULTS AND DISCUSSION}

A GWAS approach was used to identify QTL affecting milk FA composition in IS and IH cows and to assess genetic differences or similarities between those 2 breeds. In this regard, this is the first GWAS on FA composition in IS because other similar studies focused on either milk production and related quality traits (Capomaccio et al., 2015a) or the lactation curve (Macciotta et al., 2015).

\section{Phenotype and Genotype Statistics}

The 2 populations displayed normal (or near-normal) distributions for all FA, which suggests complexity of their genetic variation. The final data set, assembled with information about farm, milk yield, fat and protein content, DIM, parity, SCC, and FA composition, is reported in Supplemental Table S1 (https://doi.org/10 $.3168 /$ jds.2018-14413). A summary of FA profile measures and significant differences between the 2 populations is reported in Supplemental Table S2 (https: //doi.org/10.3168/jds.2018-14413). The predominant FA were C16:0, C18:1 cis-9, C14:0, and C18:0 in both breeds. Although it is not possible to state which milk is healthier or superior without reference to the ulti- mate consumer, the comparison between the 2 breeds supports that the FA profiles differ significantly. Interesting differences $(P<0.05)$ between breeds were observed for almost all FA considered (73 of $83 ; 88 \%$ ), with particularly high significance levels $(P<0.0001)$ for 65 traits (Supplemental Table S2).

As our study is the first comparative analysis of milk FA content between the IS and IH breeds, there are no similar studies in the literature for direct comparison of our findings. More broadly, however, milk fat comparisons are extensive in the literature for Holstein, Brown Swiss, and Jersey cows under different feeding regimens (DePeters et al., 1995; Kelsey et al., 2003; Moore et al., 2005; Carroll et al., 2006; Palladino et al., 2010; Nantapo et al., 2014). Moreover, 2 recent studies reported information about milk fat in Simmental cows. Pilarczyk et al. (2015) compared the milk fat content of Simmental and Holstein-Friesian cows under the same feeding regimen (organic farming) and found the concentration of PUFA n- 6 to be higher in Simmental cows, whereas they observed no difference in the content of SFA and MUFA. A comparison of milk FA composition in Polish Simmental and Holstein cows by Adamska et al. (2016) reported higher contents of short-chain SFA in Polish Simmental milk fat. In our study, milk SFA concentration was higher $(+2.5 \%)$ in IS than in IH, whereas MUFA concentration was lower $(-6 \%)$ in IS milk. In particular, among SFA, we found short- and medium-chain FA to be significantly higher in IS milk, whereas the C18:0 content was higher in IH milk fat. Furthermore, the concentrations of longchain FA were higher in IH. In terms of the PUFA content, the n- 6 content was higher $(+10 \%)$ in IS milk fat, whereas the $n-3$ content was higher $(+20 \%)$ in IH.

Differences between the 2 breeds were also confirmed in terms of heritability of the traits of interest, particularly the estimated values for short-chain SFA (i.e., C6:0, C8:0, C10:0, and C14:0). Moderate heritability values were found for $\mathrm{C} 16: 1$ cis-9 and $\mathrm{C} 18: 0$, for DI $10-1 /(10+10-1)$ and DI $14-1 /(14+14-1)$, and for DI $\mathrm{rum} /(\mathrm{vac}+\mathrm{rum})$, where rum is rumenic acid and vac is vaccenic acid, but only in IS. A summary of all heritability values is reported in Supplemental Table S3 (https://doi.org/10.3168/jds.2018-14413). Generally, the estimated heritability results confirmed the good partitioning of the observed variation into unobserved genetic and environmental factors. In particular, the estimated values indicate that genetic components contribute especially to SFA metabolic traits, as we expected (Mele et al., 2007; Schennink et al., 2009b; Bilal et al., 2014). Considering single FA heritability results, our values were higher compared with those reported by other authors (Mele et al., 2009). However, herita- 
bility estimates are always specific for the investigated population, and they are also influenced by sample size and sampling purpose (in our case, GWAS analysis).

\section{Single-Population Genome-Wide Association Studies Results}

From the single-marker GWAS on 83 FA traits, we identified 6 and 90 significant SNP (i.e., over the Bonferroni threshold) in IS and IH, respectively (Supplemental Table S4; https://doi.org/10.3168/jds.2018 -14413). More specifically, the few significant associations in IS were detected on chromosomes BTA19 and BTA26 for the C14:0, C14:1 cis-9, DI 10-1/(10+10-1), and DI $14-1 /(14+14-1)$ traits (Figure 1$)$, whereas for $\mathrm{IH}$, multiple signals were detected on BTA26 for the C14:1 cis-9, DI 10-1/(10+10-1), and DI $14-1 /(14+14-$ 1) traits (Figure 2).

The low number of SNP associated with the IS FA profile trait is not surprising; in fact, in previous analyses, lower number of significant SNP associated with productive traits were found in IS compared with IH, due to lower LD among markers (Capomaccio et al., 2015a). Generally, complex traits such as FA profiles (Bionaz and Loor, 2008; Buitenhuis et al., 2014) are affected by a few major genes with large effects and by many other genes with moderate to small effects. The latter are not easily identified by genome-wide scans in modern cattle breeds mainly because of sample size limitations. In addition, signals from the major genes are lost due to the fixation of favorable alleles (Capomaccio et al., 2015a). The differences we detected between the 2 breeds, in terms of GWAS results, are consistent with the different genetic backgrounds of IS and IH (Bomba et al., 2015; Marras et al., 2015). The significant signals on BTA19 $(\sim 51.3 \mathrm{Mb})$ and BTA26 $(\sim 22.0 \mathrm{Mb})$ are likely related to the effects of the FASN (chromosome 19, AC_000176.1, 51384892-51403614) and SCD (chromosome 26, AC_000183.1, 2113794521148317) genes, involved in FA biosynthesis and UFA biosynthesis, respectively. At the same time, it is interesting to note that we detected no signals for FA traits on chromosome BTA14, where DGAT1 is located. The importance of the DGAT1 gene in lactation has been widely described (Grisart et al., 2002), so when we examined milk FP, we found significant associations on IH BTA14 $(\sim 15.3, \sim 18.2, \sim 29.5$, and $\sim 41.4 \mathrm{Mb})$ but not on IS BTA14 (Supplemental Figure S1, Supplemental Table S5; https://doi.org/10.3168/jds.2018-14413). The IH associations are clearly due to DGAT1 (chromosome 14, AC_000171.1, 1795425-1804838). The absence of DGAT1 signal in the IS breed is in line with previous studies, in which the DGAT1 p.232K allele was identified at very low frequency in IS (Scotti et al.,
2010), a condition that precludes association with the FP trait in IS (Capomaccio et al., 2015a).

\section{Gene-Based Association Analysis Results}

As outlined in the introduction, with the aim of overcoming the stringent GWAS significance threshold, we amplified the single-marker association signals by processing them through our gene-centric MUGBAS procedure (Capomaccio et al., 2015b). Manhattan plots showing gene association signals discovered by MUGBAS are depicted in Supplemental Figures S2 and S3 (https://doi.org/10.3168/jds.2018-14413). A summary of all significant genes and each one's best SNP is given in Supplemental Table S6 (https://doi.org/10 .3168/jds.2018-14413). The MUGBAS identified lists of 47 and 165 significant positional candidate genes associated with milk FA in IS and $\mathrm{IH}$, respectively, revealing distinct patterns of genes associated with the traits of interest (Table 1). In this regard, the $S C D$ gene, responsible for the conversion of saturated C10: 0-C18:0 FA to MUFA, showed significant associations with C14:1 cis-9, DI $10-1 /(10+10-1)$, and DI $14-1 /$ $(14+14-1)$ in both breeds, and with C10:1 cis-9, C16:1 cis-9, and DI $16-1 /(16+16-1)$ specifically in IS. These results are consistent with those of other studies where significant SCD associations were detected: in Italian Holstein Friesian with DI $14-1 /(14+14-1)$ (Mele et al., 2007); in Jersey, Piedmontese, and Valdostana with C14:1 and C10:1 (Moioli et al., 2007); in Dutch Holstein-Friesian with DI $10-1 /(10+10-1)$, DI $12-1 /$ $(12+12-1)$, DI $14-1 /(14+14-1)$, DI $16-1 /(16+16-1)$, and DI 18-1/(18+18-1) (Schennink et al., 2008); in Italian Brown with C14:1 cis-9 and DI 14-1/(14+14-1) (Conte et al., 2010); in Holstein with C10:1, C12:1, and C14:1 (Bouwman et al., 2011); in Danish Holstein with C14:1 and DI 14-1/(14+14-1); and in Danish Jersey with DI 14-1/(14+14-1) (Buitenhuis et al., 2014). The $D G A T 1$ gene, pivotal in mammary gland triacylglycerol synthesis and known to underlie large genetic variation in milk-fat production and composition of dairy cows (Grisart et al., 2002), was associated only in IH with the C15:0, C16:0, and $\mathrm{C} 16: 1$ cis-9 traits, as we expected based on previous results (Scotti et al., 2010; Capomaccio et al., 2015a). Our results for the IH breed are consistent with the findings of Buitenhuis et al. (2014) in the Danish Holstein and Danish Jersey breeds, who reported DGAT1 to be associated with C16:0 and C16:1, but not with the DI. However, we note that significant associations between DGAT1 and DI have been reported in other studies on the Italian Brown and Dutch Holstein breeds (Schennink et al., 2008; Conte et al., 2010). Moreover, it is worth noting that ARSBFGL-NGS-4939, our best candidate SNP associated 

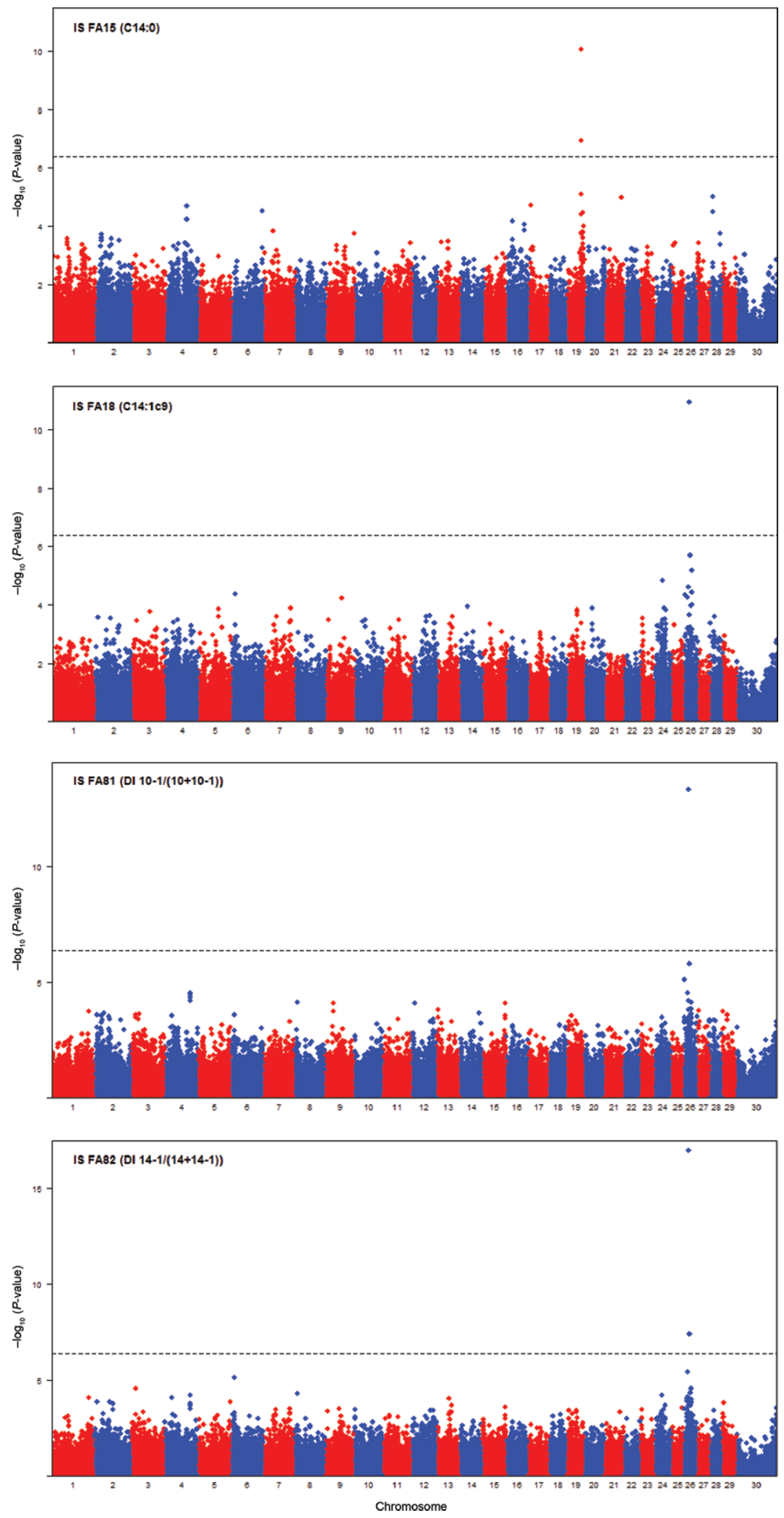

Figure 1. Manhattan plots of genome-wide association study results showing the significance of SNP associations for C14:0, C14:1 cis-9 (c9), desaturation index (DI) 10-1/(10+10-1), and DI 14-1/(14+14-1) fatty acid (FA) traits in the Italian Simmental (IS) breed. Negative log 10 $P$-values of all SNP that passed quality control are plotted against their genomic positions. Different chromosomes are distinguished with different colors. The dashed line indicates the Bonferroni-corrected genome-wide significance threshold at $P$-value 0.05 . Color version available online. 

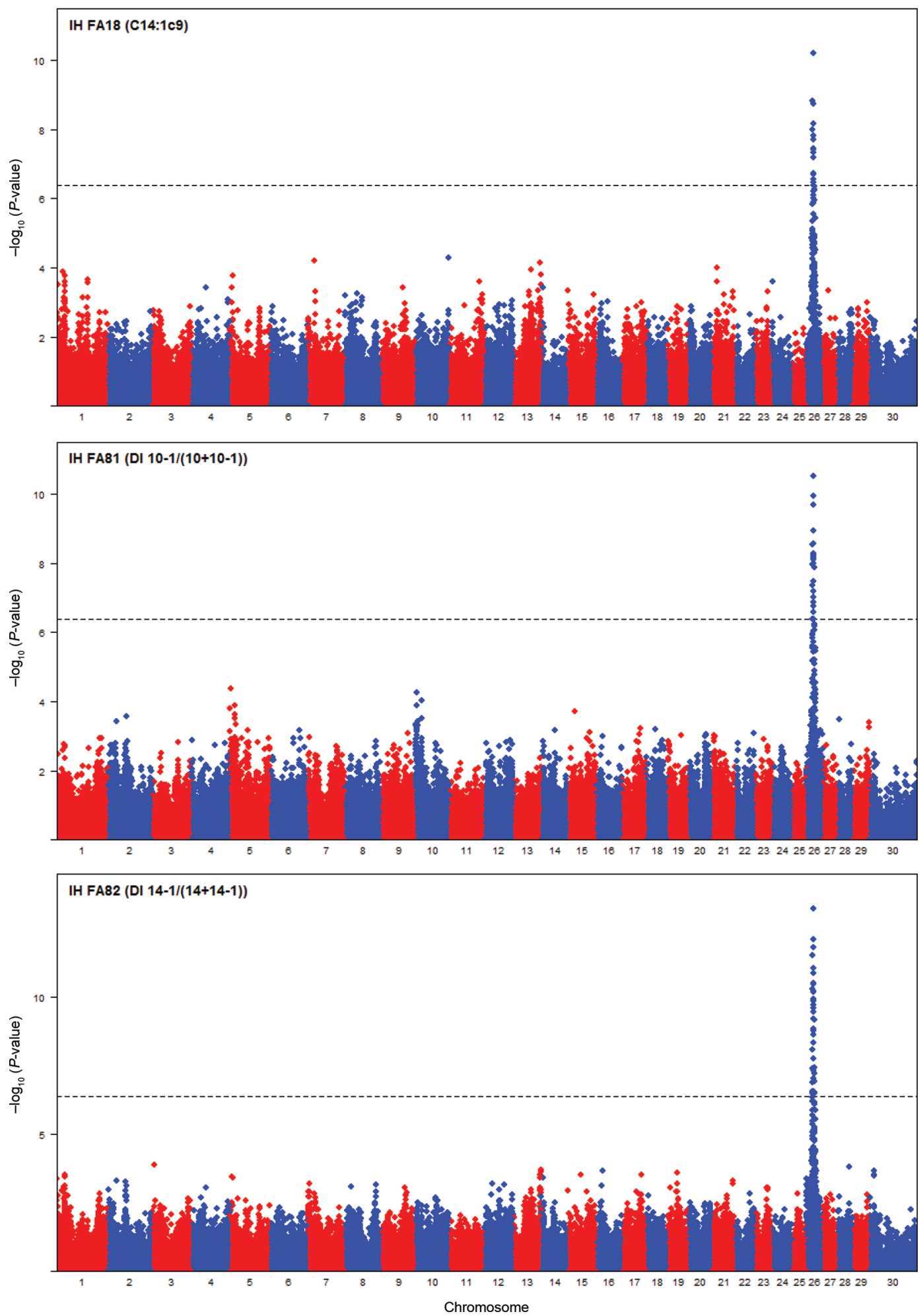

Figure 2. Manhattan plots of genome-wide association study results showing the significance of SNP associations for C14:1 cis-9 (c9), desaturation index (DI) $10-1 /(10+10-1)$, and DI) $=14-1 /(14+14-1)$ fatty acid (FA) traits in the Italian Holstein $(\mathrm{IH})$ breed. Negative $\log _{10} P$-values of all SNP that passed quality control are plotted against their genomic positions. Different chromosomes are distinguished with different colors. The dashed line indicates the Bonferroni-corrected genome-wide significance threshold at $P$-value 0.05 . Color version available online. 
with DGAT1 in the C15:0 trait (Supplemental Table S6; https://doi.org/10.3168/jds.2018-14413), was already shown to be in complete LD with the DGAT1 p.232K polymorphism in the German Holstein-Friesian breed (Wang et al., 2012) and to be associated with milk FP in IH (Capomaccio et al., 2015a). This SNP had a low frequency (0.063) in our IS population, confirming previous findings (Scotti et al., 2010; Capomaccio et al., 2015a).

Another interesting and unexpected result was the lack of association of FASN in IH breed with the de novo FA synthesis associated traits (e.g., C10:0, C12:0, and C14:0), whereas it was found in IS. FASN was reported in other studies as a candidate gene for milk FP and fat composition (Schennink et al., 2009a; Bouwman et al., 2012). In particular, Schennink et al. (2009a) found an association between FASN and C14:0 in the Holstein Friesian breed. This may suggest that FASN variants are of minor importance (i.e., small allelic effects) for overall milk fat composition in IH, compared with other genes, or simply that the FASN effect might be masked by the major effects of the $S C D$ and $D G A T 1$ variants in our analysis. Related to this, BovineHD1900014372, our best SNP associated with the FASN effect on the C10:0 and C12:0 traits (Supplemental Table S6), was already found to be significantly associated with FA in other breeds (Bouwman et al., 2012). In our study, this SNP had similar frequencies in both breeds $(0.397$ in IS and 0.375 in $\mathrm{IH})$. Further analyses are required to investigate the effects of $F A S N$ variants on milk fat

Table 1. Summary of significant genes (i.e., false discovery rate q-values less than or equal to 0.05) obtained with multispecies gene-based association suite analysis categorized for each chromosome (Chr), breed, and fatty acid (FA)

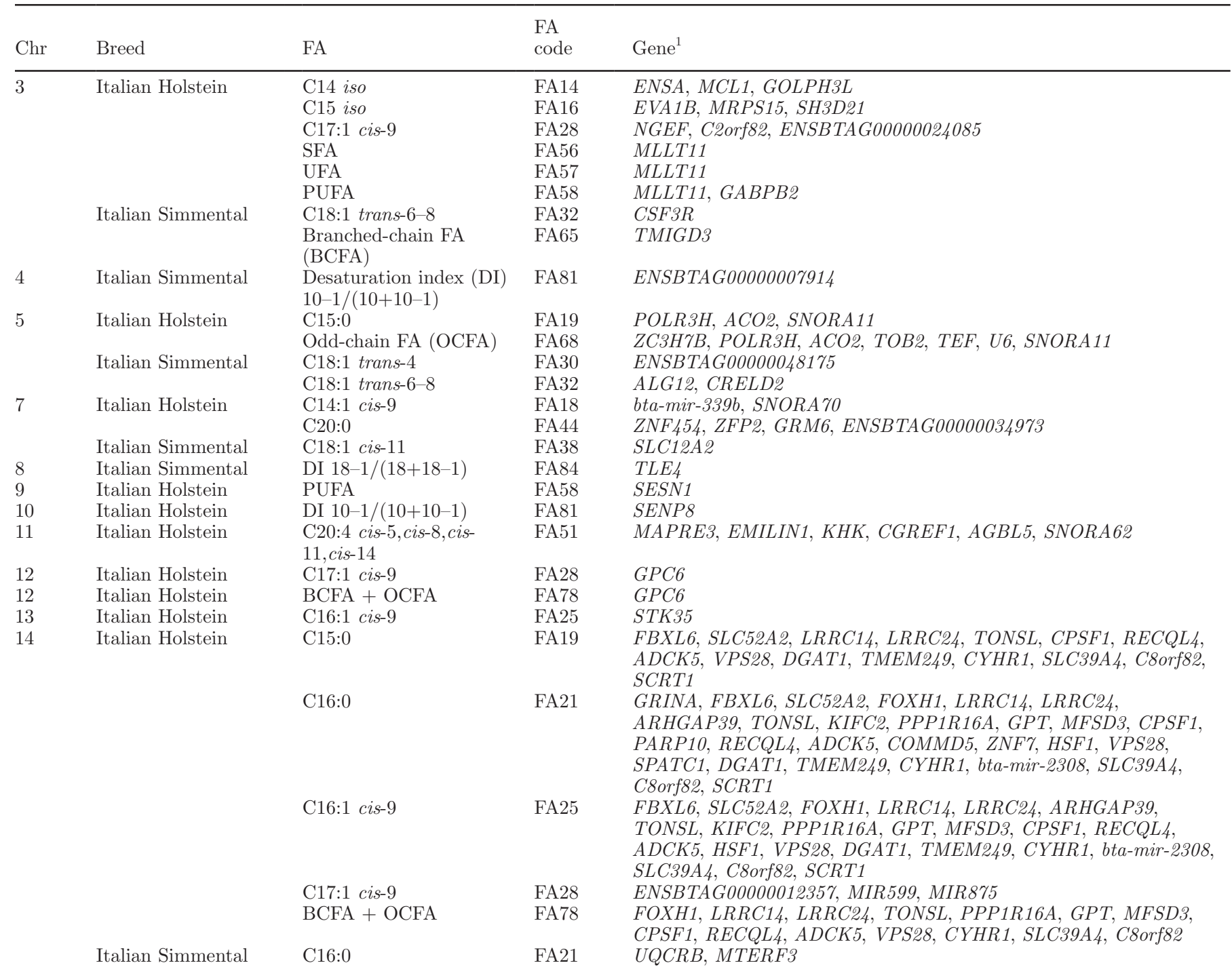


Table 1 (Continued). Summary of significant genes (i.e., false discovery rate q-values less than or equal to 0.05) obtained with multispecies gene-based association suite analysis categorized for each chromosome (Chr), breed, and fatty acid (FA)

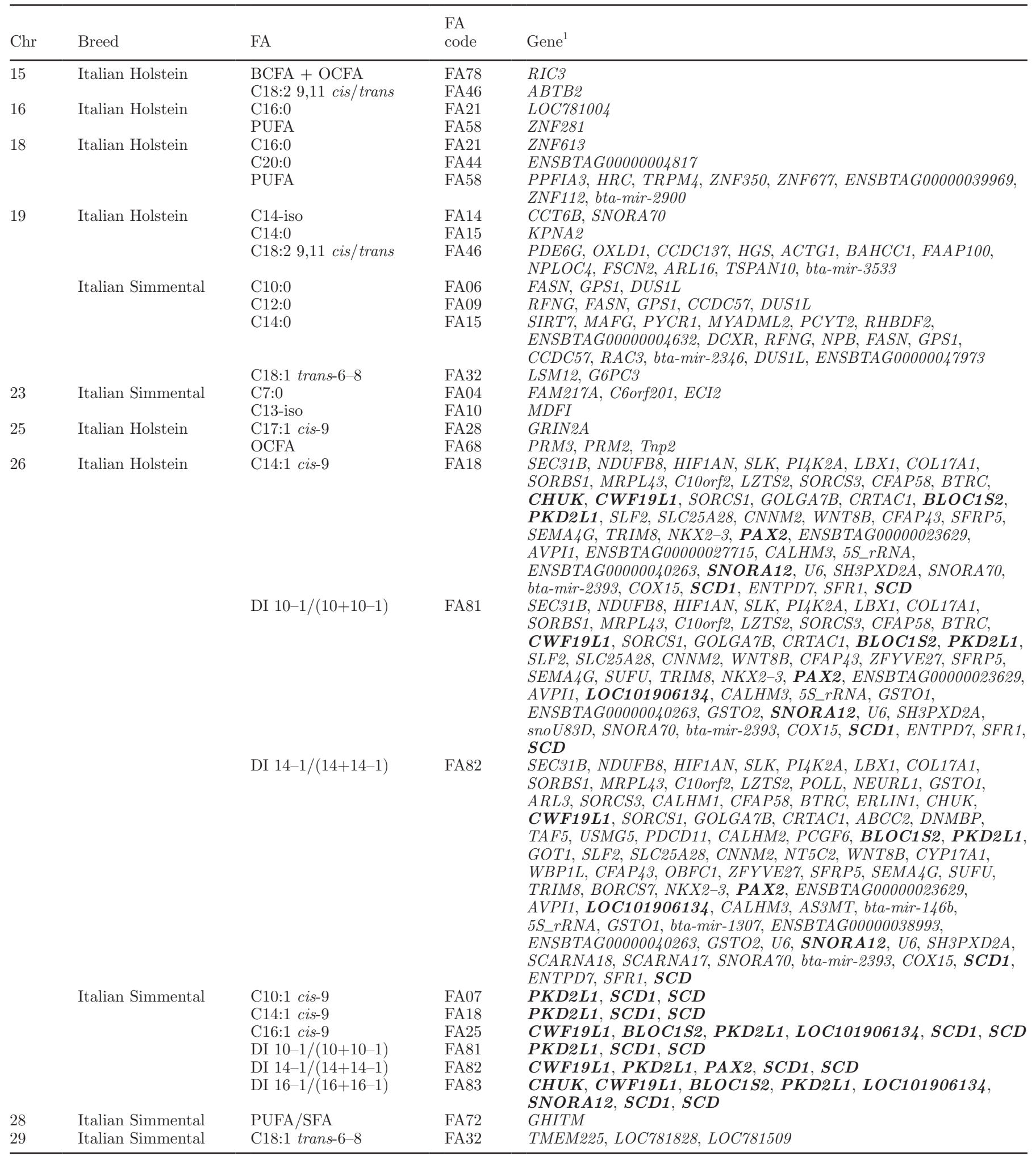

${ }^{1}$ Significant genes overlapping between the 2 breeds are shown in bold. 
composition in IS and IH, whereas it remains a candidate gene for milk production traits (Schennink et al., 2009a; Bouwman et al., 2012). Other interesting candidate genes highlighted by MUGBAS but not by PIA were coiled-coil domain containing 57 (CCDC57), sorbin and SH3 domain containing 1 (SORBS1), and conserved helix-loop-helix ubiquitous kinase ( $C H U K)$. The $C C D C 57$ on IS BTA19 was associated with the C12:0 and C14:0 traits. The CCDC57 gene is expressed in cow mammary gland (Medrano et al., 2010), and the coiled-coil domains refer to protein structural motifs. Our result is in agreement with the significant association outcomes on C14:0 obtained by Bouwman et al. (2014). The SORBS1 gene encodes an important protein in the insulin-signaling pathway in the adipose depots of humans and has a positive regulatory effect on lipid biosynthesis (Baumann et al., 2000; Yang et al., 2003; Li et al., 2014). In Chinese Holstein cows, Li et al. (2014) found 2 SNP associated with C14:1 cis-9 and DI 14-1/(14+14-1) located close to the SORBS1 gene. In our study was associated with the C14:1 cis-9, DI $10-1 /(10+10-1)$, and DI $14-1 /(14+14-1)$ traits in IH on BTA 26. On BTA 26 the CHUK gene was associated with the DI $16-1 /(16+16-1)$ trait in the IS population and with C14:1 cis-9 and DI $14-1 /(14+14-1)$ in the IH population. Also, Li et al. (2014) found an association of this gene with the DI $14-1 /(14+14-1)$ trait, but they considered their result to be an artifact due to the close proximity of $C H U K$ to the $S C D$ gene. The descriptions of the other significant genes discovered by MUGBAS but not revealed in PIA are reported in Supplemental Table S7 (https://doi.org/10.3168/jds.2018-14413).

\section{Pathway Analysis Results}

To reduce false-positive signals and focus on meaningful results, we performed a gene pathway analysis using our in-house method named PIA [V. Palombo, M. Milanesi, G. Sferra (Dipartimento di Bioscienze e Territorio, Università degli Studi del Molise, Pesche, Italy), S. Capomaccio, S. Sgorlon, and M. D'Andrea, unpublished data]. This approach helped to confirm the functional roles of significant genes obtained by MUGBAS. A summary of all genes highlighted by PIA for the 3 degrees of interaction we investigated is given in Supplemental Table S8 (https://doi.org/10.3168/jds .2018-14413). Among the significant genes identified by MUGBAS (and excluding well-known major lipogenic genes, discussed above), PIA highlighted 7 and 9 additional candidate genes in IS and IH, respectively, with putative roles in pathways related to "Lipid metabolism" in KEGG or interacting with them (Figures 3 and 4). The originality of this approach lies in its capacity to investigate many levels of interactions among the pathways related to the trait of interest, revealing potential functional connections that otherwise are difficult to identify.

Overall, our PIA results confirmed the presence of differences between the 2 breeds in terms of genes associated with milk FA profile (Supplemental Table S8). In this regard, at the first level of interaction, along with the expected effects of the $S C D, F A S N$, and DGAT1 genes, we detected significant signals for ECI2, PCYT2, and DCXR in IS and CYP17A1 in IH. More specifically, the IS ECI2 gene (on chromosome BTA23) was found to be associated with the C7:0 trait. This gene (enoyl-CoA delta isomerase 2) codes for an auxiliary mitochondrial enzyme involved in UFA oxidation (van Weeghel et al., 2012), that is, in the degradation of FA during $\beta$-oxidation, as highlighted by the PIA. In particular, the ECI2 enzyme converts a cis-double bond to a trans-double bond so that $\beta$-oxidation may continue. It is interesting to note that the significant association of this gene was detected only in IS, in which we measured a higher milk n-6 FA content compared with IH.

The DCXR and PCYT2 genes, on IS BTA19 and involved in "Arachidonic acid metabolism" and "Glycerophospholipid metabolism," respectively, were found to be associated with the C14:0 trait. In particular, $D C X R$ is well conserved through evolution and encodes dicarbonyl L-xylulose reductase, a member of the shortchain dehydrogenase/reductase superfamily, which reduces various $\alpha$-dicarbonyl compounds involved in the formation of advanced glycation end products (Nakagawa et al., 2002). Dicarbonyl compounds originate from sugars or lipids and are generated in various biological systems by oxidative stress (Lee et al., 2013). PCYT2 encodes ethanolamine-phosphate cytidylyltransferase 2 involved in the synthesis of phosphatidylethanolamine from diacylglycerol. In human adipose tissue, PCYT2 expression is negatively correlated with fat mass percentage and body mass index (Sharma et al., 2013). In this regard, it is interesting that both genes are on BTA19 and closely linked to FASN, separated by only $\sim 63.1$ and $\sim 122.8 \mathrm{~kb}$, respectively. This could suggest that these are false positive signals (Supplemental Table S8), although the MUGBAS showed that these 2 genes have 2 different best SNP distinct from FASN (i.e., ARS-BFGL-NGS-39983 and ARS-BFGL-NGS-90673). The LD among the 3 SNP is very low (i.e., the maximum $r^{2}$ value is 0.09 ), suggesting the possibility that the 3 genes are associated with the C14:0 trait.

The CYP17A1 gene, on IH BTA26, was found to be associated with the DI $14-1 /(14+14-1)$ trait.

Cytochrome P450 family 17 subfamily A member 1 (CYP17A1) encodes a key enzyme in the synthesis and metabolism of steroid hormones, and the Hotta et al. (2012) genetic association study revealed that the 
CYP17A1 together with the NT5C2 gene (see below) influence a reduction in both visceral and subcutaneous fat mass in human, whereas in Wang et al. (2018) CYP17A1 has been associated with type 2 diabetes mellitus.

Focusing on the second-degree interactions (Supplemental Table S8), we detected the IS G6PC3 gene on BTA19 as being the best candidate and having a significant association with the C18:1 trans-6-8 trait (Table 1). The G6PC3 was shown by PIA to be connected to the "Glycolysis/Gluconeogenesis pathway" and to "Starch and sucrose metabolism" at the second and third levels of interaction, respectively. G6PC3 encodes a glucose-6-phosphatase that catalyzes the final step of gluconeogenesis with the hydrolysis of glucose6-phosphate, and is ubiquitously expressed in humans (Banka and Newman, 2013). Regarding the IH breed, we detected at the second level of interaction a significant association of aconitase 2 (ACO2), on BTA5, with the C15:0 and odd-chain fatty acid (OCFA) traits. ACO2, considered a best candidate gene in our results, encodes a protein which acts in the mitochondrion to catalyze the interconversion of citrate to isocitrate via cis-aconitate in the second step of the tricarboxylic acid cycle. On IH BTA26, we detected significant associations of phosphatidylinositol 4-kinase type 2 alpha (PI4K2A) with the C14:1 cis-9, DI $10-1 /(10+10-1)$, and DI $14-1 /(14+14-1)$ traits. Human PI KK2A was investigated for a possible link to autosomal recessive hereditary spastic paraplegia since a knockout model mouse showed this phenotype (Cleeter et al., 2011). Its product is an enzyme involved in vesicle formation in the trans-Golgi network and in endosomes (Albanesi et al., 2015).

At the third level of interaction, PIA uncovered 2 genes (PYCR1 and ALG12) in IS, and 6 genes (GOT1, GPT, NT5C2, PDE6G, POLR3H, and COX15) in IH. The PYCR1, on IS BTA19, was found to be associated with the C14:0 trait, and PIA placed it in the "Arginine and proline metabolism" pathway. The gene product, pyrroline-5-carboxylate reductase 1 , is involved in proline synthesis and metabolism related to the tricarboxylic acid cycle, the urea cycle, and the pentose phosphate pathway, and has been associated with tumor proliferation in several human studies (Guernsey et al., 2009; Possemato et al., 2011; Cai et al., 2018). Asparaginelinked glycosylation 12 homolog (ALG12), on IS BTA5, was shown by PIA to be in the "N-Glycan biosynthesis"
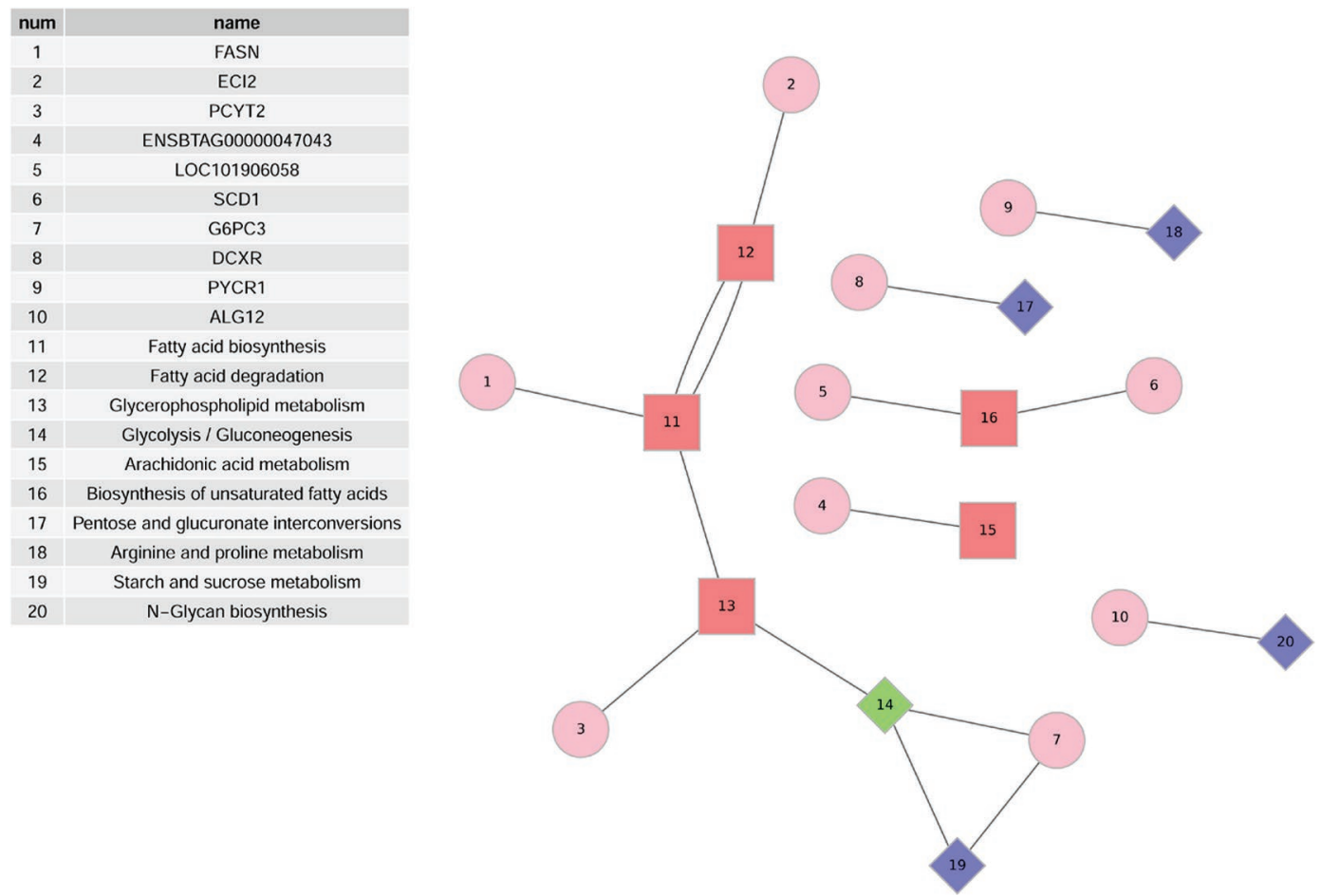

Figure 3. Diagram showing the results obtained with pathway interaction analysis (PIA) on multi-species gene-based association suite (MUGBAS) significant genes for the Italian Simmental breed. The circles represent functional candidate genes falling inside the pathways associated with the trait of interest or interacting with the pathway. The squares represent first-degree (FDI) interaction pathways, directly connected to the trait of interest (i.e., "Lipid metabolism" in the Kyoto Encyclopedia of Genes and Genomes). The light gray (green) and dark gray (blue) diamond symbols represent second- and third-level pathways, respectively, interacting with FDI pathways, as highlighted by the PIA. Color version available online. 

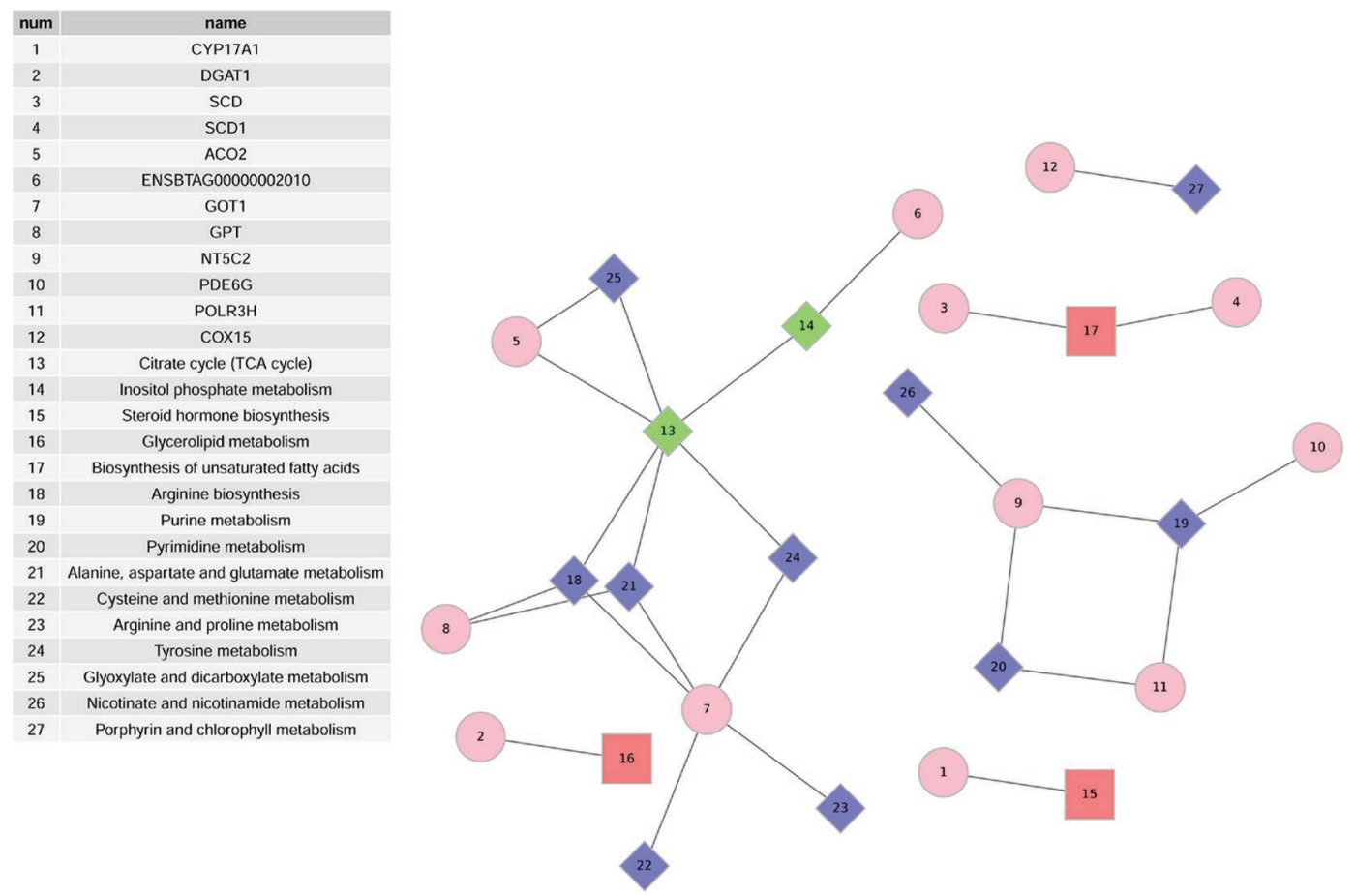

Figure 4. Diagram showing the results obtained with pathway interaction analysis (PIA) on multi-species gene-based association suite (MUGBAS) significant genes for the Italian Holstein breed. The circles represent functional candidate genes falling inside the pathways associated with the trait of interest or interacting with the pathway. The squares represent the first-degree interaction (FDI) pathway, directly connected to the trait of interest (i.e., "Lipid metabolism" in the Kyoto Encyclopedia of Genes and Genomes). The light gray (green) and dark gray (blue) diamond symbols represent the second- and third-level pathways, respectively, interacting with FDI pathways, as highlighted by the PIA. Color version available online.

pathway and considered by MUGBAS as the best candidate gene associated with the $\mathrm{C} 18: 1$ trans- $6-8$ trait. A study of $A L G 12$ expression in mouse cell lines revealed different transcriptional activities related to different promoter mutations (Oh-Hashi et al., 2013). Regarding the IH breed, PIA revealed a cluster of genes in "Purine metabolism," "Pyrimidine metabolism," and "Alanine, aspartate and glutamate metabolism: NT5C2, GPT, and COX15. 5'-Nucleotidase, cytosolic II (NT5C2), on BTA26, was found to be associated with the DI 14-1/ $(14+14-1)$ trait and considered by MUGBAS as the best candidate gene. The NT5C2 encodes a protein involved in purine metabolism. The NT5C is a family of enzymes that inhibits basal lipid oxidation and glucose transport in skeletal muscle. Reduction of NT5C expression or enzyme activity may promote metabolic flexibility in type 2 diabetes (Kulkarni et al., 2011). Glutamic-pyruvic transaminase (GPT), on IS BTA14, was found to be associated with the C16:0, C16:1 cis-9, and branched-chain fatty acid (BCFA) + OCFA traits. Serum GPT level is a clinically important indicator of liver function in many studies testing different diets or supplements (Liao et al., 2013). Cytochrome c oxidase (COX15), on IS BTA26, is associated with the C14:1 cis-9, DI $10-1 /(10+10-1)$, and DI $14-1 /(14+14-1)$ traits. The COX15 is the terminal component of the mitochondrial respiratory chain, catalyzing the electron transfer from reduced cytochrome c to oxygen, and functional and genetic studies have demonstrated that its deficiency causes cardiomyopathy (Antonicka et al., 2003; Fedida et al., 2017). As to the IH breed, we found significant associations of POLR3H, on BTA5, with C15:0 and OCFA. Polymerase (RNA) III subunit $\mathrm{H}(P O L R 3 H)$ gene expression level has been studied in pigs, where the authors suggested different strategies for energy use in skeletal muscle and adipose tissue in different residual feed intake swine lines (low and high; Gondret et al., 2017).

\section{CONCLUSIONS}

Combining GWAS with a gene-centric approach (MUGBAS) and PIA allowed us to delineate genomic regions and novel genes associated with FA profiles in the IS and IH breeds. The PIA highlighted candidate genes on 4 chromosomes in the IS breed (BTA05, BTA19, BTA23, and BTA26) and 4 chromosomes in IH breed (BTA05, BTA14, BTA19, and BTA26) for 
8 FA and 3 DI in IS [C7:0, C10:0, C10:1 cis-9, C12:0, C14:0, C14:1 cis-9, C16:1 cis-9, C18:1 trans-6-8, DI $10-1 /(10+10-1)$, DI $14-1 /(14+14-1)$, and DI $16-1 /$ $(16+16-1)]$ and for $7 \mathrm{FA}$ and $2 \mathrm{DI}$ in IH [C14:1 cis-9, C15:0, C16:0, C16:1 cis-9, C18:2 9-11 cis/trans, OCFA and BCFA + OCFA, DI 10-1/(10+10-1), and DI 14-1/ $(14+14-1)]$. Moreover, our results support the effects of 3 well-described genes (SCD, DGAT1, and FASN) on milk fat yield and content. Furthermore, this study revealed other possible candidate genes, several of them directly or indirectly involved in "Lipid metabolism," as ECI2, PCYT2, DCXR, G6PC3, PYCR1, and ALG12 in IS, and CYP17A1, ACO2, PI4K2A, GOT1, GPT, NT5C2, PDE6G, POLR3H, and COX15 in IH. In summary, the findings reported here improve our understanding of the genetic architecture of the milk FA profile in IS and IH cows and highlight breed-specific genomic features.

\section{ACKNOWLEDGMENTS}

Research was supported by the Italian Ministero dell'Istruzione, dell'Università e della Ricerca (Rome, Italy; PRIN - GEN2PHEN project). Marco Milanesi was supported by grant 2016/05787-7, São Paulo Research Foundation (FAPESP, Brazil).

\section{REFERENCES}

Adamska, A., J. Rutkowska, and W. Przybylski. 2016. Comparison of fatty acid composition of milk from Simmental and Polish Holstein-Friesian cows in different production seasons. Ann. Anim. Sci. 16:1211-1225. https://doi.org/10.1515/aoas-2016-0040.

Albanesi, J., H. Wang, H.-Q. Sun, B. Levine, and H. Yin. 2015. GABARAP-mediated targeting of PI4K2A/PI4KII $\alpha$ to autophagosomes regulates PtdIns4P-dependent autophagosome-lysosome fusion. Autophagy 11:2127-2129. https://doi.org/10.1080/15548627 .2015.1093718.

Alexander, D. H., J. Novembre, and K. Lange. 2009. Fast model-based estimation of ancestry in unrelated individuals. Genome Res. 19:1655-1664. https://doi.org/10.1101/gr.094052.109.

Antonicka, H., A. Mattman, C. G. Carlson, D. M. Glerum, K. C. Hoffbuhr, S. C. Leary, N. G. Kennaway, and E. A. Shoubridge. 2003. Mutations in COX15 produce a defect in the mitochondrial heme biosynthetic pathway, causing early-onset fatal hypertrophic cardiomyopathy. Am. J. Hum. Genet. 72:101-114. https://doi.org/ 10.1086/345489.

Aulchenko, Y. S., D.-J. de Koning, and C. Haley. 2007a. Genomewide rapid association using mixed model and regression: A fast and simple method for genomewide pedigree-based quantitative trait loci association analysis. Genetics 177:577-585. https://doi.org/10 .1534 /genetics.107.075614.

Aulchenko, Y. S., S. Ripke, A. Isaacs, and C. M. van Duijn. 2007b. GenABEL: An R library for genome-wide association analysis. Bioinformatics 23:1294-1296. https://doi.org/10.1093/bioinformatics/ btm108.

Banka, S., and W. G. Newman. 2013. A clinical and molecular review of ubiquitous glucose-6-phosphatase deficiency caused by G6PC3 mutations. Orphanet J. Rare Dis. 8:84. https://doi.org/10.1186/ $1750-1172-8-84$.

Baumann, C. A., V. Ribon, M. Kanzaki, D. C. Thurmond, S. Mora, S. Shigematsu, P. E. Bickel, J. E. Pessin, and A. R. Saltiel. 2000.
CAP defines a second signalling pathway required for insulin-stimulated glucose transport. Nature 407:202-207. https://doi.org/10 $.1038 / 35025089$.

Bilal, G., R. I. Cue, A. F. Mustafa, and J. F. Hayes. 2014. Short communication: Genetic parameters of individual fatty acids in milk of Canadian Holsteins. J. Dairy Sci. 97:1150-1156. https://doi.org/ 10.3168/jds.2012-6508.

Bionaz, M., and J. J. Loor. 2008. Gene networks driving bovine milk fat synthesis during the lactation cycle. BMC Genomics 9:366. https://doi.org/10.1186/1471-2164-9-366.

Bomba, L., E. L. Nicolazzi, M. Milanesi, R. Negrini, G. Mancini, F. Biscarini, A. Stella, A. Valentini, and P. Ajmone-Marsan. 2015. Relative extended haplotype homozygosity signals across breeds reveal dairy and beef specific signatures of selection. Genet. Sel. Evol. 47:25. https://doi.org/10.1186/s12711-015-0113-9.

Bouwman, A. C., H. Bovenhuis, M. H. P. W. Visker, and J. A. M. van Arendonk. 2011. Genome-wide association of milk fatty acids in Dutch dairy cattle. BMC Genet. 12:43. https://doi.org/10.1186/ 1471-2156-12-43.

Bouwman, A. C., M. H. Visker, J. A. van Arendonk, and H. Bovenhuis. 2012. Genomic regions associated with bovine milk fatty acids in both summer and winter milk samples. BMC Genet. 13:93. https://doi.org/10.1186/1471-2156-13-93.

Bouwman, A. C., M. H. P. W. Visker, J. M. van Arendonk, and H. Bovenhuis. 2014. Fine mapping of a quantitative trait locus for bovine milk fat composition on Bos taurus autosome 19. J. Dairy Sci. 97:1139-1149. https://doi.org/10.3168/jds.2013-7197.

Browning, B. L., and S. R. Browning. 2016. Genotype imputation with millions of reference samples. Am. J. Hum. Genet. 98:116-126. https://doi.org/10.1016/j.ajhg.2015.11.020.

Browning, S. R., and B. L. Browning. 2007. Rapid and accurate haplotype phasing and missing-data inference for whole-genome association studies by use of localized haplotype clustering. Am. J. Hum. Genet. 81:1084-1097. https://doi.org/10.1086/521987.

Buccioni, A., M. Pauselli, C. Viti, S. Minieri, G. Pallara, V. Roscini, S. Rapaccini, M. T. Marinucci, P. Lupi, G. Conte, and M. Mele. 2015. Milk fatty acid composition, rumen microbial population, and animal performances in response to diets rich in linoleic acid supplemented with chestnut or quebracho tannins in dairy ewes. J. Dairy Sci. 98:1145-1156. https://doi.org/10.3168/jds.2014-8651.

Buccioni, A., S. Rapaccini, M. Antongiovanni, S. Minieri, G. Conte, and M. Mele. 2010. Conjugated linoleic acid and C18:1 isomers content in milk fat of sheep and their transfer to Pecorino Toscano cheese. Int. Dairy J. 20:190-194. https://doi.org/10.1016/j.idairyj 2009.10.001.

Buitenhuis, B., L. L. Janss, N. A. Poulsen, L. B. Larsen, M. K. Larsen, and P. Sørensen. 2014. Genome-wide association and biological pathway analysis for milk-fat composition in Danish Holstein and Danish Jersey cattle. BMC Genomics 15:1112. https://doi.org/10 $.1186 / 1471-2164-15-1112$.

Cai, F., Y. Miao, C. Liu, T. Wu, S. Shen, X. Su, and Y. Shi. 2018. Pyrroline-5-carboxylate reductase 1 promotes proliferation and inhibits apoptosis in non-small cell lung cancer. Oncol. Lett. 15:731740. https://doi.org/10.3892/ol.2017.7400.

Capomaccio, S., M. Milanesi, L. Bomba, K. Cappelli, E. L. Nicolazzi, J. L. Williams, P. Ajmone-Marsan, and B. Stefanon. 2015a. Searching new signals for production traits through gene-based association analysis in three Italian cattle breeds. Anim. Genet. 46:361-370. https://doi.org/10.1111/age.12303.

Capomaccio, S., M. Milanesi, L. Bomba, E. Vajana, and P. AjmoneMarsan. 2015b. MUGBAS: a species free gene-based programme suite for post-GWAS analysis. Bioinformatics 31:2380-2381. https: //doi.org/10.1093/bioinformatics/btv144.

Carroll, S. M., E. J. DePeters, S. J. Taylor, M. Rosenberg, H. PerezMonti, and V. A. Capps. 2006. Milk composition of Holstein, Jersey, and Brown Swiss cows in response to increasing levels of dietary fat. Anim. Feed Sci. Technol. 131:451-473. https://doi.org/ 10.1016/j.anifeedsci.2006.06.019.

Christie, W. W. 1982. A simple procedure of rapid transmethylation of glycerolipids and cholesteryl esters. J. Lipid Res. 23:1072-1075. 
Cleeter, M., H. Houlden, P. Simons, R. Al-Shawi, G. Stevanin, A. Durr, J. Hsuan, and T. T. Warner. 2011. Screening for mutations in the phosphatidylinositol 4-kinase 2-alpha gene in autosomal recessive hereditary spastic paraplegia. Amyotroph. Lateral Scler. 12:148-149. https://doi.org/10.3109/17482968.2010.543689.

Conte, G., M. Mele, S. Chessa, B. Castiglioni, A. Serra, G. Pagnacco, and P. Secchiari. 2010. Diacylglycerol acyltransferase 1, stearoyl$\mathrm{CoA}$ desaturase 1 , and sterol regulatory element binding protein 1 gene polymorphisms and milk fatty acid composition in Italian Brown cattle. J. Dairy Sci. 93:753-763. https://doi.org/10.3168/ jds.2009-2581.

D'Andrea, M., S. Dal Monego, A. Pallavicini, M. Modonut, R. Dreos, B. Stefanon, and F. Pilla. 2011. Muscle transcriptome profiling in divergent phenotype swine breeds during growth using microarray and RT-PCR tools. Anim. Genet. 42:501-509. https://doi.org/10 .1111/j.1365-2052.2010.02164.x.

DePeters, E. J., J. F. Medrano, and B. A. Reed. 1995. Fatty acid composition of milk fat from three breeds of dairy cattle. Can. J. Anim. Sci. 75:267-269. https://doi.org/10.4141/cjas95-040.

Esposito, G.. F. Masucci, F. Napolitano, A. Braghieri, R. Romano, N. Manzo, and A. Di Francia. 2014. Fatty acid and sensory profiles of Caciocavallo cheese as affected by management system. J. Dairy Sci. 97:1918-1928. https://doi.org/10.3168/jds.2013-7292.

FAO. 2010. Fats and fatty acids in human nutrition. Report of an expert consultation. FAO Food Nutr. Pap. 91:1-166.

Fedida, J., V. Fressart, P. Charron, E. Surget, T. Hery, P. Richard, E. Donal, B. Keren, G. Duthoit, F. Hidden-Lucet, E. Villard, and E. Gandjbakhch. 2017. Contribution of exome sequencing for genetic diagnostic in arrhythmogenic right ventricular cardiomyopathy/dysplasia. PLoS One 12:e0181840. https://doi.org/10.1371/ journal.pone.0181840.

Fenelon, M. A., and T. P. Guinee. 1999. The effect of milk fat on Cheddar cheese yield and its prediction, using modifications of the van Slyke cheese yield formula. J. Dairy Sci. 82:2287-2299. https: //doi.org/10.3168/jds.S0022-0302(99)75477-9.

Gilmour, A. R., B. J. Gogel, B. R. Cullis, and R. Thompson. 2009. ASReml User Guide Release 3.0. VSN Int. Ltd., Hemel Hempstead, UK.

Gondret, F., A. Vincent, M. Houée-Bigot, A. Siegel, S. Lagarrigue, D. Causeur, H. Gilbert, and I. Louveau. 2017. A transcriptome multitissue analysis identifies biological pathways and genes associated with variations in feed efficiency of growing pigs. BMC Genomics 18:244. https://doi.org/10.1186/s12864-017-3639-0.

Grisart, B., W. Coppieters, F. Farnir, L. Karim, C. Ford, P. Berzi, N. Cambisano, M. Mni, S. Reid, P. Simon, R. Spelman, M. Georges, and R. Snell. 2002. Positional candidate cloning of a QTL in dairy cattle: identification of a missense mutation in the bovine DGAT1 gene with major effect on milk yield and composition. Genome Res. 12:222-231. https://doi.org/10.1101/gr.224202.

Guernsey, D. L., H. Jiang, S. C. Evans, M. Ferguson, M. Matsuoka, M. Nightingale, A. L. Rideout, S. Provost, K. Bedard, A. Orr, M.-P. Dubé, M. Ludman, and M. E. Samuels. 2009. Mutation in pyrroline-5-carboxylate reductase 1 gene in families with cutis laxa type 2. Am. J. Hum. Genet. 85:120-129. https://doi.org/10.1016/ j.ajhg.2009.06.008.

Haug, A., A. T. Høstmark, and O. M. Harstad. 2007. Bovine milk in human nutrition-A review. Lipids Health Dis. 6:25. https://doi .org/10.1186/1476-511X-6-25.

Hotta, K., A. Kitamoto, T. Kitamoto, S. Mizusawa, H. Teranishi, T. Matsuo, Y. Nakata, H. Hyogo, H. Ochi, T. Nakamura, S. Kamohara, N. Miyatake, K. Kotani, R. Komatsu, N. Itoh, I. Mineo, J. Wada, M. Yoneda, A. Nakajima, T. Funahashi, S. Miyazaki, K. Tokunaga, H. Masuzaki, T. Ueno, K. Chayama, K. Hamaguchi, K. Yamada, T. Hanafusa, S. Oikawa, H. Yoshimatsu, T. Sakata, K. Tanaka, Y. Matsuzawa, K. Nakao, and A. Sekine. 2012. Genetic variations in the CYP17A1 and NT5C2 genes are associated with a reduction in visceral and subcutaneous fat areas in Japanese women. J. Hum. Genet. 57:46-51. https://doi.org/10.1038/jhg .2011 .127 .

Kanehisa, M., and S. Goto. 2000. KEGG: Kyoto Encyclopedia of Genes and Genomes. Nucleic Acids Res. 28:27-30.
Kelsey, J. A., B. A. Corl, R. J. Collier, and D. E. Bauman. 2003. The effect of breed, parity, and stage of lactation on conjugated linoleic acid (CLA) in milk fat from dairy cows. J. Dairy Sci. 86:25882597. https://doi.org/10.3168/jds.S0022-0302(03)73854-5.

Kulkarni, S. S., H. K. R. Karlsson, F. Szekeres, A. V. Chibalin, A. Krook, and J. R. Zierath. 2011. Suppression of 5'-nucleotidase enzymes promotes AMP-activated protein kinase (AMPK) phosphorylation and metabolism in human and mouse skeletal muscle. J. Biol. Chem. 286:34567-34574. https://doi.org/10.1074/jbc .M111.268292.

Lee, S.-K., L. T. Son, H.-J. Choi, and J. Ahnn. 2013. Dicarbonyl/l-xylulose reductase (DCXR): The multifunctional pentosuria enzyme. Int. J. Biochem. Cell Biol. 45:2563-2567. https://doi.org/10.1016/ j.biocel.2013.08.010.

Li, C., D. Sun, S. Zhang, S. Wang, X. Wu, Q. Zhang, L. Liu, Y. Li, and L. Qiao. 2014. Genome wide association study identifies 20 novel promising genes associated with milk fatty acid traits in Chinese Holstein. PLoS One 9:e96186. https://doi.org/10.1371/ journal.pone.0096186.

Liao, C.-C. T.-T. Ou, C.-H. Wu, and C.-J. Wang. 2013. Prevention of diet-induced hyperlipidemia and obesity by caffeic acid in C57BL/6 mice through regulation of hepatic lipogenesis gene expression. J. Agric. Food Chem. 61:11082-11088. https://doi.org/ 10.1021/jf4026647.

Macciotta, N. P. P., G. Gaspa, L. Bomba, D. Vicario, C. Dimauro, M. Cellesi, and P. Ajmone-Marsan. 2015. Genome-wide association analysis in Italian Simmental cows for lactation curve traits using a low-density (7K) SNP panel. J. Dairy Sci. 98:8175-8185. https:/ /doi.org/10.3168/jds.2015-9500.

Marras, G., G. Gaspa, S. Sorbolini, C. Dimauro, P. Ajmone-Marsan, A. Valentini, J. L. Williams, and N. P. P. Macciotta. 2015. Analysis of runs of homozygosity and their relationship with inbreeding in five cattle breeds farmed in Italy. Anim. Genet. 46:110-121. https://doi.org/10.1111/age.12259.

Martini, M., F. Salari, and I. Altomonte. 2016. The macrostructure of milk lipids: The fat globules. Crit. Rev. Food Sci. Nutr. 56:1209 1221. https://doi.org/10.1080/10408398.2012.758626.

Medrano, J., G. Rincon, and A. Islas-Trejo. 2010. Comparative analysis of bovine milk and mammary gland transcriptome using RNASeq. Page 125 in Proc. 9th World Congr. Genet. Appl. Livest. Prod., Leipzig, Germany. German Society for Animal Science, Neustadt, Germany.

Mele, M., G. Conte, B. Castiglioni, S. Chessa, N. P. P. Macciotta, A. Serra, A. Buccioni, G. Pagnacco, and P. Secchiari. 2007. Stearoylcoenzyme A desaturase gene polymorphism and milk fatty acid composition in Italian Holsteins. J. Dairy Sci. 90:4458-4465. https: //doi.org/10.3168/jds.2006-617.

Mele, M., R. Dal Zotto, M. Cassandro, G. Conte, A. Serra, A. Buccioni, G. Bittante, and P. Secchiari. 2009. Genetic parameters for conjugated linoleic acid, selected milk fatty acids, and milk fatty acid unsaturation of Italian Holstein-Friesian cows. J. Dairy Sci 92:392-400. https://doi.org/10.3168/jds.2008-1445.

Moioli, B., G. Contarini, A. Avalli, G. Catillo, L. Orrù, G. De Matteis, G. Masoero, and F. Napolitano. 2007. Short communication: Effect of stearoyl-coenzyme A desaturase polymorphism on fatty acid composition of milk. J. Dairy Sci. 90:3553-3558. https://doi .org/10.3168/jds.2006-855.

Moore, C. E., J. K. Kay, R. J. Collier, M. J. Vanbaale, and L. H. Baumgard. 2005. Effect of supplemental conjugated linoleic acids on heat-stressed Brown Swiss and Holstein cows. J. Dairy Sci. 88:1732-1740. https://doi.org/10.3168/jds.S0022-0302(05)72846 -0 .

Nakagawa, J., S. Ishikura, J. Asami, T. Isaji, N. Usami, A. Hara T. Sakurai, K. Tsuritani, K. Oda, M. Takahashi, M. Yoshimoto, N. Otsuka, and K. Kitamura. 2002. Molecular characterization of mammalian dicarbonyl/L-xylulose reductase and its localization in kidney. J. Biol. Chem. 277:17883-17891. https://doi.org/10.1074/ jbc.M110703200.

Nantapo, C. T. W., V. Muchenje, and A. Hugo. 2014. Atherogenicity index and health-related fatty acids in different stages of lactation from Friesian, Jersey and Friesian $\times$ Jersey cross cow milk under a 
pasture-based dairy system. Food Chem. 146:127-133. https://doi .org/10.1016/j.foodchem.2013.09.009.

Oh-Hashi, K., T. Tejima, Y. Hirata, and K. Kiuchi. 2013. Characterization of the 5 '-flanking region of the mouse asparagine-linked glycosylation 12 homolog gene. Cell. Mol. Biol. Lett. 18:315-327. https://doi.org/10.2478/s11658-013-0091-2.

Palladino, R. A., F. Buckley, R. Prendiville, J. J. Murphy, J. Callan, and D. A. Kenny. 2010. A comparison between Holstein-Friesian and Jersey dairy cows and their $\mathrm{F}(1)$ hybrid on milk fatty acid composition under grazing conditions. J. Dairy Sci. 93:2176-2184. https://doi.org/10.3168/jds.2009-2453.

Parodi, P. W. 1999. Conjugated linoleic acid and other anticarcinogenic agents of bovine milk fat. J. Dairy Sci. 82:1339-1349. https: //doi.org/10.3168/jds.S0022-0302(99)75358-0.

Pegolo, S., N. Mach, Y. Ramayo-Caldas, S. Schiavon, G. Bittante, and A. Cecchinato. 2018. Integration of GWAS, pathway and network analyses reveals novel mechanistic insights into the synthesis of milk proteins in dairy cows. Sci. Rep. 8:566. https://doi.org/10 .1038/s41598-017-18916-4.

Pilarczyk, R., J. Wójcik, P. Sablik, and P. Czerniak. 2015. Fatty acid profile and health lipid indices in the raw milk of Simmental and Holstein-Friesian cows from an organic farm. S. Afr. J. Anim. Sci. 45:30-38. https://doi.org/10.4314/sajas.v45i1.4.

Possemato, R., K. M. Marks, Y. D. Shaul, M. E. Pacold, D. Kim, K. Birsoy, S. Sethumadhavan, H.-K. Woo, H. G. Jang, A. K. Jha, W. W. Chen, F. G. Barrett, N. Stransky, Z.-Y. Tsun, G. S. Cowley, J. Barretina, N. Y. Kalaany, P. P. Hsu, K. Ottina, A. M. Chan, B. Yuan, L. A. Garraway, D. E. Root, M. Mino-Kenudson, E. F. Brachtel, E. M. Driggers, and D. M. Sabatini. 2011. Functional genomics reveal that the serine synthesis pathway is essential in breast cancer. Nature 476:346-350. https://doi.org/10.1038/ nature10350.

Pulina, G., A. H. D. Francesconi, B. Stefanon, A. Sevi, L. Calamari, N. Lacetera, V. Dell'Orto, F. Pilla, P. A. Marsan, M. Mele, F. Rossi, G. Bertoni, G. M. Crovetto, and B. Ronchi. 2017. Sustainable ruminant production to help feed the planet. Ital. J. Anim. Sci. 16:140-171. https://doi.org/10.1080/1828051X.2016.1260500.

R Development Core Team. 2006. R: A language and environment for statistical computing. R Foundation for Statistical Computing, Vienna, Austria. http://www.R-project.org/.

Raven, L.-A., B. G. Cocks, and B. J. Hayes. 2014. Multibreed genome wide association can improve precision of mapping causative variants underlying milk production in dairy cattle. BMC Genomics 15:62. https://doi.org/10.1186/1471-2164-15-62.

Schennink, A., H. Bovenhuis, K. M. Léon-Kloosterziel, J. M. van Arendonk, and M. H. P. W. Visker. 2009a. Effect of polymorphisms in the FASN, OLR1, PPARGC1A, PRL and STAT5A genes on bovine milk-fat composition. Anim. Genet. 40:909-916. https:// doi.org/10.1111/j.1365-2052.2009.01940.x.

Schennink, A., J. M. L. Heck, H. Bovenhuis, M. H. P. W. Visker, H. J. F. van Valenberg, and J. M. van Arendonk. 2008. Milk fatty acid unsaturation: genetic parameters and effects of stearoyl-CoA desaturase (SCD1) and acyl CoA: diacylglycerol acyltransferase 1 (DGAT1). J. Dairy Sci. 91:2135-2143. https://doi.org/10.3168/jds .2007-0825.

Schennink, A., W. M. Stoop, M. H. P. W. Visker, J. M. L. Heck, H. Bovenhuis, J. J. van der Poel, H. J. F. van Valenberg, and J. M. van Arendonk. 2007. DGAT1 underlies large genetic variation in milk-fat composition of dairy cows. Anim. Genet. 38:467-473. https://doi.org/10.1111/j.1365-2052.2007.01635.x.

Schennink, A., W. M. Stoop, M. H. P. W. Visker, J. J. van der Poel, H. Bovenhuis, and J. M. van Arendonk. 2009b. Short communication: Genome-wide scan for bovine milk-fat composition. II. Quantitative trait loci for long-chain fatty acids. J. Dairy Sci. 92:4676-4682. https://doi.org/10.3168/jds.2008-1965.

Schwingshackl, L., and G. Hoffmann. 2012. Monounsaturated fatty acids and risk of cardiovascular disease: Synopsis of the evidence available from systematic reviews and meta-analyses. Nutrients 4:1989-2007. https://doi.org/10.3390/nu4121989.

Scotti, E., L. Fontanesi, F. Schiavini, V. L. Mattina, A. Bagnato, and V. Russo. 2010. DGAT1 p.K232A polymorphism in dairy and dual purpose Italian cattle breeds. Ital. J. Anim. Sci. 9:e16. https://doi .org/10.4081/ijas.2010.e16.

Sharma, N. K., K. A. Langberg, A. K. Mondal, and S. K. Das. 2013. Phospholipid biosynthesis genes and susceptibility to obesity: analysis of expression and polymorphisms. PLoS One 8. https:// doi.org/10.1371/journal.pone.0065303.

Shingfield, K. J., M. Bonnet, and N. D. Scollan. 2013. Recent developments in altering the fatty acid composition of ruminant-derived foods. Animal 7(Suppl 1):132-162. https://doi.org/10.1017/ S1751731112001681.

Stoop, W. M., A. Schennink, M. H. P. W. Visker, E. Mullaart, J. M. van Arendonk, and H. Bovenhuis. 2009. Genome-wide scan for bovine milk-fat composition. I. Quantitative trait loci for short- and medium-chain fatty acids. J. Dairy Sci. 92:4664-4675. https://doi .org/10.3168/jds.2008-1966.

Tullo, E., E. Frigo, A. Rossoni, R. Finocchiaro, M. Serra, N. Rizzi, A. B. Samorè, F. Canavesi, M. G. Strillacci, R. T. M. M. Prinsen, and A. Bagnato. 2014. Genetic parameters of fatty acids in Italian Brown Swiss and Holstein cows. Ital. J. Anim. Sci. 13:3208. https: //doi.org/10.4081/ijas.2014.3208.

Utsunomiya, Y. T., M. Milanesi, A. T. H. Utsunomiya, R. B. P. Torrecilha, E.-S. Kim, M. S. Costa, T. S. Aguiar, S. Schroeder, A. S. do Carmo, R. Carvalheiro, H. H. R. Neves, R. C. M. Padula, T. S. Sussai, L. B. Zavarez, R. S. Cipriano, M. M. T. Caminhas, G. Hambrecht, L. Colli, E. Eufemi, P. Ajmone-Marsan, D. Cesana, M. Sannazaro, M. Buora, M. Morgante, G. Liu, D. Bickhart, C. P. Van Tassell, J. Sölkner, T. S. Sonstegard, and J. F. Garcia. 2017. A PLAG1 mutation contributed to stature recovery in modern cattle. Sci. Rep. 7:17140. https://doi.org/10.1038/s41598-017 $-17127-1$.

van den Berg, I., D. Boichard, and M. S. Lund. 2016. Comparing power and precision of within-breed and multibreed genome-wide association studies of production traits using whole-genome sequence data for 5 French and Danish dairy cattle breeds. J. Dairy Sci. 99:8932-8945. https://doi.org/10.3168/jds.2016-11073.

van Weeghel, M., H. te Brinke, H. van Lenthe, W. Kulik, P. E. Minkler, M. S. K. Stoll, J. O. Sass, U. Janssen, W. Stoffel, K. O. Schwab, R. J. A. Wanders, C. L. Hoppel, and S. M. Houten. 2012. Functional redundancy of mitochondrial enoyl-CoA isomerases in the oxidation of unsaturated fatty acids. FASEB J. Off. Publ. Fed. Am. Soc. Exp. Biol. 26:4316-4326. https://doi.org/10.1096/fj.12 -206326 .

Wang, L., Y.-M. Niu, S.-S. Wu, C. Zhang, L. Zhou, H.-X. Zuo, and P. Wang. 2018. A study on the association between polymorphisms in the cytochrome P450 family 17 subfamily a member 1 gene region and type 2 diabetes mellitus in Han Chinese. Front. Endocrinol. (Lausanne) 9:323. https://doi.org/10.3389/fendo.2018.00323.

Wang, X., C. Wurmser, H. Pausch, S. Jung, F. Reinhardt, J. Tetens, G. Thaller, and R. Fries. 2012. Identification and dissection of four major QTL affecting milk fat content in the German HolsteinFriesian population. PLoS One 7:e40711. https://doi.org/10.1371/ journal.pone.0040711.

Yang, W.-S., W.-J. Lee, K.-C. Huang, K.-C. Lee, C.-L. Chao, C.-L. Chen, T.-Y. Tai, and L.-M. Chuang. 2003. mRNA levels of the insulin-signaling molecule SORBS1 in the adipose depots of nondiabetic women. Obes. Res. 11:586-590. https://doi.org/10.1038/ oby. 2003.82

Zhang, W., J. Zhang, L. Cui, J. Ma, C. Chen, H. Ai, X. Xie, L. Li, S. Xiao, L. Huang, J. Ren, and B. Yang. 2016. Genetic architecture of fatty acid composition in the longissimus dorsi muscle revealed by genome-wide association studies on diverse pig populations. Genet. Sel. Evol. 48:5. https://doi.org/10.1186/s12711-016-0184-2. 